\title{
Axonal Sprouting and Formation of Terminals in the Adult Cerebellum during Associative Motor Learning
}

\author{
Henk-Jan Boele, ${ }^{1}$ Sebastiaan K. E. Koekkoek, ${ }^{1}$ Chris I. De Zeeuw, ${ }^{1,2}$ and Tom J. H. Ruigrok ${ }^{1}$ \\ ${ }^{1}$ Department of Neuroscience, Erasmus University Medical Center, 3000 DR Rotterdam, The Netherlands, and ${ }^{2}$ Netherlands Institute for Neuroscience, \\ Royal Academy of Arts and Sciences, 1105 BA Amsterdam, The Netherlands
}

Plastic changes in the efficacy of synapses are widely regarded to represent mechanisms underlying memory formation. So far, evidence for learning-dependent, new neuronal wiring is limited. In this study, we demonstrate that pavlovian eyeblink conditioning in adult mice can induce robust axonal growth and synapse formation in the cerebellar nuclei. This de novo wiring is both condition specific and region specific because it does not occur in pseudoconditioned animals and is particularly observed in those parts of the cerebellar nuclei that have been implicated to be involved in this form of motor learning. Moreover, the number of new mossy fiber varicosities in these parts of the cerebellar nuclei is positively correlated with the amplitude of conditioned eyelid responses. These results indicate that outgrowth of axons and concomitant occurrence of new terminals may, in addition to plasticity of synaptic efficacy, contribute to the formation of memory.

\section{Introduction}

Synaptic and intrinsic plasticity are generally assumed to be the essential neuronal mechanisms for memory formation (Martin et al., 2000; Zhang and Linden, 2003). In vivo imaging studies are now beginning to reveal that structural synaptic plasticity processes, such as growth and retraction of dendritic spines, might also critically contribute to memory formation (Holtmaat and Svoboda, 2009). Up to now, evidence is limited for learninginduced neuronal reorganizations at a larger scale, such as axonal growth over longer distances and new synapse formation.

An appropriate learning paradigm for investigating these potential neuronal reorganizations would be pavlovian eyeblink conditioning, because the neuroanatomical circuits involved in this conditioning task have been described in great detail previously (McCormick and Thompson 1984; Jirenhed et al., 2007; Mostofi et al., 2010). During eyeblink conditioning, a neutral conditioned stimulus (CS), usually a tone, is followed by an eyeblink-eliciting unconditioned stimulus (US), such as an air puff applied to the eye. Repeated pairings of tone and air puff gradually lead to the development of a timed eyelid closure in response to the tone, which is called the conditioned response (CR). The US is relayed by climbing fibers from specific parts of

Received Feb. 1, 2013; revised 0ct. 3, 2013; accepted 0ct. 8, 2013.

Author contributions: H.-J.B., C.I.D.Z., and T.J.H.R. designed research; H.-J.B. and T.J.H.R. performed research; H.-J.B. and T.J.H.R. contributed unpublished reagents/analytic tools; H.-J.B., S.K.E.K., and T.J.H.R. analyzed data; H.-J.B., S.K.E.K., C.I.D.Z., and T.J.R. wrote the paper.

This work was supported by the Dutch Organization for Medical Sciences, Life Sciences (NeuroBasic) Center, the European Research Council Advanced, CEREBNET, and C7 programs of the European Community (all to C.I.D.Z.). We are grateful to E. Sabel-Goedknegt for histological work, H. Van Den Burg for technical assistance, and M. Nagtzaam for assistance with eyeblink data analyses.

The authors declare no competing financial interests.

Correspondence should be addressed to Chris I. De Zeeuw, Department of Neuroscience, Erasmus University Medical Center, 3000 DR Rotterdam, The Netherlands. E-mail: c.dezeeuw@erasmusmc.nl.

DOI:10.1523/JNEUROSCI.0511-13.2013

Copyright $\odot 2013$ the authors $\quad 0270-6474 / 13 / 3317897-11 \$ 15.00 / 0$ the inferior olive to Purkinje cells (PCs) in distinctive eyeblink controlling zones of the cerebellar cortex (Hesslow, 1994; Mostofi et al., 2010) and, by way of climbing fiber collaterals, to the lateral part of the anterior interposed nucleus (AIN) of the cerebellar nuclei $(\mathrm{CN})$, including its dorsolateral hump (DLH) (Ruigrok and Voogd, 2000; Pijpers et al., 2005; Sugihara and Shinoda, 2007). The CS is relayed to the same PC zones by mossy fibers originating from the lateral part of the basilar pontine nuclei (BPN) (Kandler and Herbert 1991; Leergaard and Bjaalie, 2007; Halverson and Freeman, 2010; Mostofi et al., 2010). Interestingly, however, mossy fiber collaterals from the BPN to the lateral AIN and DLH are very sparse (Dietrichs et al., 1983; Brodal et al., 1986; Parenti et al., 2002; Cicirata et al., 2005; Fig. 1A).

During the acquisition phase of eyeblink conditioning, PCs in the relevant regions show a well-timed inhibition of their simple spike firing (Jirenhed et al., 2007), which may be induced by local synaptic and intrinsic plasticity processes (De Zeeuw and Yeo, 2005; Schonewille et al., 2010; Gao et al., 2012). Paradoxically, inactivation of PCs seems unable to completely eliminate CRs in trained animals, which has led to the suggestion that additional synaptic plasticity and thus memory formation would also take place downstream in the $\mathrm{CN}$ at later stages of the training process (Ohyama et al., 2006; Fig. 1B). However, because in naive animals mossy fiber collaterals from the lateral BPN to the DLH and adjacent part of the lateral AIN are very sparse, there is no obvious anatomical correlate for the induction of this memory here. Therefore, we investigated the hypothesis that pavlovian eyeblink conditioning can induce growth of mossy fiber collaterals onto specific target neurons in the $\mathrm{CN}$ forming a new substrate for memory formation.

\section{Materials and Methods}

Subjects and surgery. Adult mice (male, C57BL/6, $n=30,12-20$ weeks old, individually housed, food available ab libitum, $12 \mathrm{~h}$ light/dark cycles) were anesthetized with a ketamine/xylazine mixture $(10 \mathrm{mg} / \mathrm{kg}$, i.p. $)$ and 
secured in a standard mouse stereotaxic headholding device, using stub ear bars to prevent hearing damage. A craniotomy was performed, and the anterograde neuronal tract tracer biotinylated dextran-amine (10\% BDA in $0.1 \mathrm{M}$ $\mathrm{PB}, \mathrm{pH} 7.4$, molecular weight 10,000 ) was iontophoretically injected (pulses of $4 \mu \mathrm{A}, 10 \mathrm{~min}$ ) with a glass micropipette (tip opening, 8-10 $\mu \mathrm{m})$ in the lateral parts of the right BPN (bregma, -3.8 to $-4 \mathrm{~mm}$; lateral, $0.7-0.9 \mathrm{~mm}$; depth, 5.5-5.8 mm) or medial parts of the right BPN (bregma, -3.8 to $-4 \mathrm{~mm}$; lateral, 0.1-0.3 $\mathrm{mm}$; depth, 5.5-5.8 $\mathrm{mm}$ ), followed by the placement of a pedestal on the skull using Optibond prime and adhesive (Kerr) and Charisma (Heraeus Kulzer).

Eyeblink conditioning. After a recovery period of $3 \mathrm{~d}$, mice with the BDA injection in the lateral parts of the right BPN were randomly divided in a conditioned group $(n=12)$, a pseudoconditioned group $(n=5)$, and an untrained group $(n=8)$. The conditioned group was subjected to one habituation session $(\mathrm{H}-0)$, followed by five training sessions (T-1-T-5). The habituation and training were performed in the home cage of the animal. This cage was placed in a sound- and light-isolating chamber. Flexible electrical wires and tubing were connected to the pedestal on the animal's head, enabling it to move freely in his home cage during the experiment. For extra isolation, we used a background white noise of $65 \mathrm{~dB}$ in this chamber. During the habituation session, we determined for each animal the tone intensity that was just below the level at which it elicited auditory startle responses, usually between 70 and $75 \mathrm{~dB}$. This tone, with a duration of $380 \mathrm{~ms}$ (rise/fall, $25 \mathrm{~ms}$ ) and frequency of $5 \mathrm{kHz}$, was subsequently used in the training session as CS. For the conditioned group with $\mathrm{BDA}$ injection in the lateral part of the right BPN, the tone CS was repeatedly paired with a mild corneal air puff US of $30 \mathrm{~ms}$ applied to the left eye using a CS-US interval of $350 \mathrm{~ms}$. In each training session, this conditioned group received eight blocks, each consisting of one US only, six paired CS-US, and one CS-only trial. Trials were separated by an interval of $30 \pm 10 \mathrm{~s}$, and blocks were separated by $120 \pm 20 \mathrm{~s}$. One full training session took $\sim 45-60 \mathrm{~min}$. Eyelid movements were recorded with the magnetic distance measurement technique (MDMT), which makes use of a magnetsensitive chip that measures movements of a minuscule magnet $(1.5 \times 0.7 \times$ $0.5 \mathrm{~mm}$ ) that is placed on the lower eyelid of the animal. Thereby, MDMT allows high spatiotemporal detection of eyeblink kinetic profiles (for details, see Koekkoek et al., 2002).

The pseudoconditioned group received essentially the same treatments as the conditioned group, except that these mice were exposed to an explicitly unpaired presentation of the CS and the US during the five training sessions. In each daily session, which also took $\sim 45-60 \mathrm{~min}$, the pseudoconditioned group received eight blocks, each consisting of seven CS-only trials and seven US-only trials, which were presented in random order. Trials were separated by $20 \pm 10 \mathrm{~s}$, and blocks were separated by $60 \pm 10 \mathrm{~s}$. We used this pseudoconditioned control group to investigate whether changes in distribution and density of mossy fiber terminal labeling in the conditioned animals with $\mathrm{BDA}$ injection in the lateral right BPN are specifically attributable to the paired CS-US presentation rather than to the less specific aspects of the learning task, such as habituation or sensitization to the CS and US per se or the experimental procedures and setup.

The untrained group was not subjected to any additional training after surgery. This control group was used to investigate whether BDA injections in the right BPN of naive untrained animals indeed result in sparse labeling of mossy fiber terminals in the $\mathrm{CN}$ as described in previous work (Dietrichs et al., 1983; Brodal et al., 1986; Parenti et al., 2002; Cicirata et al., 2005).

Finally, a fourth group $(n=5)$ consisted of animals with BDA injected in the medial parts of the right BPN. This group received the same treatment as the conditioned group with BDA injections in the lateral right $\mathrm{BPN}$. We used this control group to investigate whether changes in distribution and density of mossy fiber terminal labeling in the $\mathrm{CN}$ occur selectively for auditory mossy fibers that originate from the lateral parts of the BPN (for a timeline of the experimental procedures, see Fig. 2).

Perfusion and histology. Ten days after BDA injection, all animals were killed with an overdose of sodium pentobarbital and transcardially perfused with an initial flush of $0.9 \%$ saline, followed by $4 \%$ paraformaldehyde in phosphate buffer, $\mathrm{pH}$ 7.4. Brains were extracted and embedded in gelatin, and sections of $40 \mu \mathrm{m}$ were made. Visualization of BDA was achieved by incubation with ABC-elite (Vector Laboratories) for 24-48 $\mathrm{h}$, followed by a DAB staining (for details, see Pijpers et al., 2005).

Analyses of behavioral data. Individual eyeblink traces were analyzed with custom computer software (LabVIEW). Trials with significant activity in the $500 \mathrm{~ms}$ pre-CS period were regarded as invalid for additional analysis. In valid trials, eyelid movements larger than three times the SD 
A

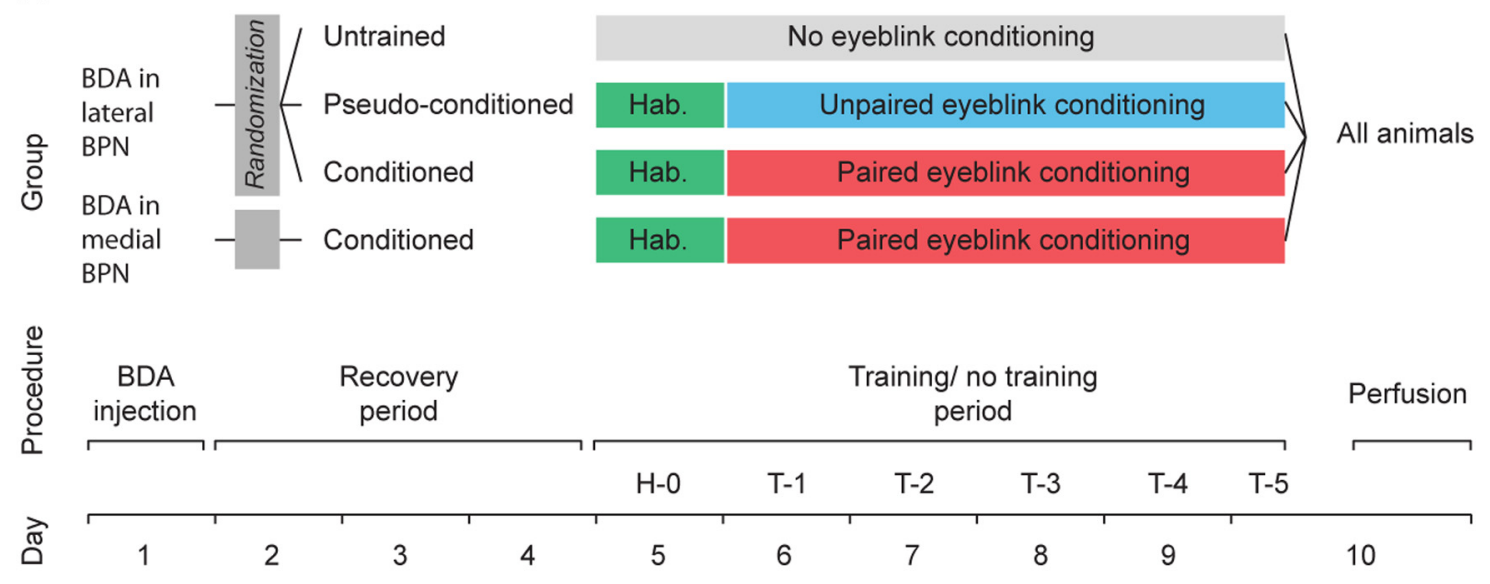

B

Habituation: 2 blocks

\begin{tabular}{|c|c|c|c|}
\hline US only (1x) ITI & CS only (7x) & $|B|$ & $\begin{array}{ll}\text { ITI: } & 30 \pm 10 \mathrm{~s} \\
\text { IBI: } & 120 \pm 10 \mathrm{~s} .\end{array}$ \\
\hline & $\sqrt{-}$ & & Stimuli random \\
\hline
\end{tabular}

Pseudo-conditioning: 8 blocks:

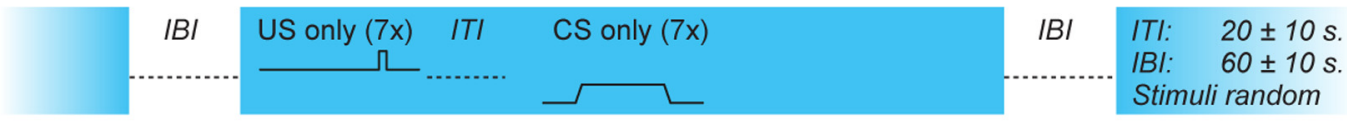

Conditioning: 8 blocks:

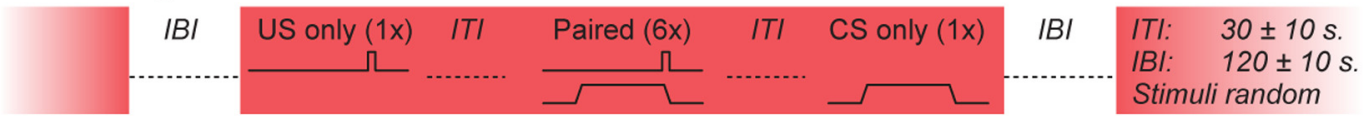

US: mild corneal air puff, $30 \mathrm{~ms}$ :

CS: auditory tone, $70-75 \mathrm{~dB}, 380 \mathrm{~ms}$ (rise \& fall $25 \mathrm{~ms}$ ):

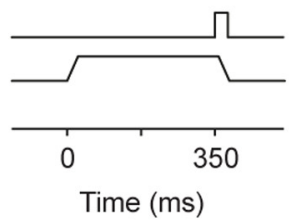

Figure 2. Scheme of experimental procedures. A, At day 1 in all groups, BDA was injected iontophoretically in the lateral or medial right BPN. After a recovery period of $3 \mathrm{~d}$, mice with BDA injected in the lateral right BPN were randomly divided in a conditioned group $(n=12)$, a pseudoconditioned group $(n=5)$, and an untrained group $(n=8)$. Mice with the BDA injection in the medial part of the right BPN ( $n=5)$ were all conditioned. Both conditioned groups were subjected to one habituation session (H-0), followed by five training sessions (T-1-T-5). The pseudoconditioned group received essentially the same treatments as the conditioned group, except that these mice were exposed to an explicitly unpaired presentation of the CS and the US. The untrained group was not subjected to any additional training after surgery. At day 10 , all animals were transcardially perfused. $\boldsymbol{B}$, Overview of the stimuli that were delivered during the habituation, pseudoconditioning, and conditioning procedures. IBI, interblock interval; ITI, intertrial interval.

of the $500 \mathrm{~ms}$ pre-CS period were considered as significant and further categorized into auditory startle response (latency to onset, 5-25 ms; latency to peak, 25-50 ms), short-latency responses (latency to onset, $50-75 \mathrm{~ms}$; latency to peak, $\sim 100-150 \mathrm{~ms}$ ), and cerebellar CRs (latency to onset, 50-350 ms; latency to peak, 150-355 ms). For CS-only trials, we used the same values, except that the latency to peak amplitude of the CR was smaller than $400 \mathrm{~ms}$ instead of $355 \mathrm{~ms}$ (for details, see Boele et al., 2010). Based on this trial-by-trial analysis, we determined for each animal the occurrence frequency of eyelid CRs per session (percentage of CRs), amplitude, and timing of the CRs and calculated mean values $( \pm$ SEM) per group. Statistical significance was determined for the percentage of CRs in the six consecutive sessions with a repeated-measures ANOVA, Bonferroni's corrected, followed by Tukey-Kramer post hoc testing. For the CR peak amplitudes, significance was determined with a paired Student's $t$ test. All statistical procedures were performed in SPSS 20.0 , and data were considered as significant if $p<0.05$.

Analyses of anatomical data. Photography of sections was performed with a Leica DMR microscope with a Leica DCR digital camera after brightness and contrast enhancements using Corel Photopaint 11.0. All sections were examined blindly by the same examiner and plotted one of two with an Olympus microscope fitted with a Lucivid miniature monitor and Neurolucida software. The injection sites in the right BPN and the contours of the BPN and the $\mathrm{CN}$ were plotted with a $2.5 \times$ objective; for every case, labeled mossy fibers in the middle cerebellar peduncle (MCP) of both sides were plotted and counted in three sections with a $20 \times$ objective. The averaged sum per section was taken as the total of labeled axons. Labeled varicosities in the $\mathrm{CN}$ were identified and plotted using a $40 \times$ objective and the motorized stage scan option of the Neurolucida software package. Axonal varicosities are the light microscopic representations of synaptic axon terminals as can be seen in electronic microscopic preparations (Wouterlood and Groenewegen, 1985; Wouterlood and Jorritsma-Byham, 1993). Because only one of two sections was plotted, the total amount per side was represented by doubling the amount of plotted varicosities. Furthermore, to allow comparison of the amount of labeled varicosities in the $\mathrm{CN}$ between animals, we divided the number of labeled varicosities in the $\mathrm{CN}$ by the averaged 
number of labeled mossy fibers in the MCP (Fig. 3). From the individual plots, usually $\sim 50$ transverse sections per animal, mean colorcoded density profiles of the $\mathrm{CN}$ were constructed for all four groups using Adobe Illustrator and LabVIEW. Statistical significance for the number of varicosities per mossy fiber in the MCP was determined with a oneway ANOVA, followed by Tukey-Kramer post hoc analysis using SPSS 20.0. Data were considered as significant if $p<0.05$.

\section{Results}

In all instances, the behavioral effect of (pseudo-)conditioning was studied for the left eye. BDA injections were always made in the right side of the BPN.

\section{Eyeblink conditioning}

Mice in both conditioned groups showed a gradual increase in the occurrence frequency of their eyelid CRs over the five consecutive training sessions, whereas pseudoconditioned animals showed no increase at all ( $p=0.0001$, ANOVA for repeated measures, Bonferroni's corrected; Tukey-Kramer post hoc: conditioned BDA lateral vs conditioned BDA medial, $p=$ 0.523 ; conditioned BDA lateral vs pseudoconditioned, $p=0.0001$; conditioned BDA medial vs pseudoconditioned, $p=0.0001$; Fig. $4 A$ ). Mice in the conditioned group with BDA injected in the lateral BPN started on average with CRs in $8.7 \pm 1.26 \%$ of the trials in the habituation session and reached on average $34.9 \pm 4.3 \%$ CRs in the fifth acquisition session ( $p=0.01$, ANOVA for repeated measures, Bonferroni's corrected; Fig. 4A). A similar increase was observed in the conditioned mice with BDA injected in the medial BPN, going from CRs in $10.8 \pm$ $1.5 \%$ of the trials during the habituation session up to $42.5 \pm 6.5 \%$ in acquisition session five $(p=0.003$, ANOVA for repeated measures, Bonferroni's corrected; Fig. 4A). As expected, mice in the pseudoconditioned group with BDA injected in the lateral BPN did not show any increase in their percentage CRs ( $p=0.431$, ANOVA for repeated measures, Bonferroni's corrected); in the habituation session, they had on average a CR in $4.6 \pm$ $1.9 \%$ of the trials and in session five, this was $4.0 \pm 1.4 \%$ (Fig. $4 A$ ). In addition, mice in the conditioned groups also learned to increase the amplitude of their eyelid CRs over the training sessions. On the first day of acquisition, when the small CRs became visible, mice in the conditioned group with BDA injected in the lateral BPN had a mean CR amplitude of $0.20 \pm 0.04 \mathrm{~mm}$, whereas on the fifth acquisition session, the mean CR amplitude was $0.41 \pm 0.06 \mathrm{~mm}(p=0.027$, paired $t$ test; Fig. $4 B, C$ ). For conditioned mice with the BDA injected in the medial BPN, those values were $0.23 \pm 0.03$ and $0.38 \pm 0.14$ $\mathrm{mm}$, respectively ( $p=0.04$, paired $t$ test; Fig. $4 B, D)$. All values express average \pm SEM.

\section{Projections from the right $\mathrm{BPN}$ to the $\mathrm{CN}$}

Neuronal projections from the lateral BPN to the contralateral (i.e., left) and ipsilateral (right) $\mathrm{CN}$ in untrained animals were sparse and mostly limited to the lateral cerebellar nucleus (LCN) and caudolateral part of the posterior interposed nuclei (PIN; Figs. 5A, 6A; Tables 1,2). BDA injections in the right BPN labeled on average a total of $120 \pm 30$ mossy fibers counted within the MCP of both sides. Per MCP labeled fiber, we counted for the total left $\mathrm{CN}$, which is ipsilateral to the US, on average $3.67 \pm 1.39$ varicosities (corrected for plotting every other section). For the total right $\mathrm{CN}$, i.e., contralateral to the US, we counted per labeled fiber on average $0.79 \pm 0.25$ varicosities. For both sides, most of these varicosities were found in the LCN (bilateral LCN, $2.21 \pm 0.49$; left LCN, $1.64 \pm 0.48$; right $\mathrm{LCN}$, $0.57 \pm 0.22$ ) and caudolateral parts of the PIN (bilateral PIN, $1.24 \pm 0.50$; left PIN, $1.11 \pm 0.50$; right PIN, $0.13 \pm 0.07)$. In untrained animals, labeled varicosities in the DLH were extremely sparse (bilateral DLH, $0.16 \pm 0.08$; left DLH, $0.11 \pm$ 0.07 ; right $\mathrm{DLH}, 0.05 \pm 0.04)$. All values express the average \pm SEM number of plotted varicosities $\times 2$ in the specific parts of the $\mathrm{CN}$ per total number of labeled fiber in the left and right MCP.

In pseudoconditioned animals, projections from the lateral right $\mathrm{BPN}$ to the $\mathrm{CN}$ showed more or less the same labeling pattern as untrained animals (Figs. 5B, 6B; Tables 1, 2). In this 
A
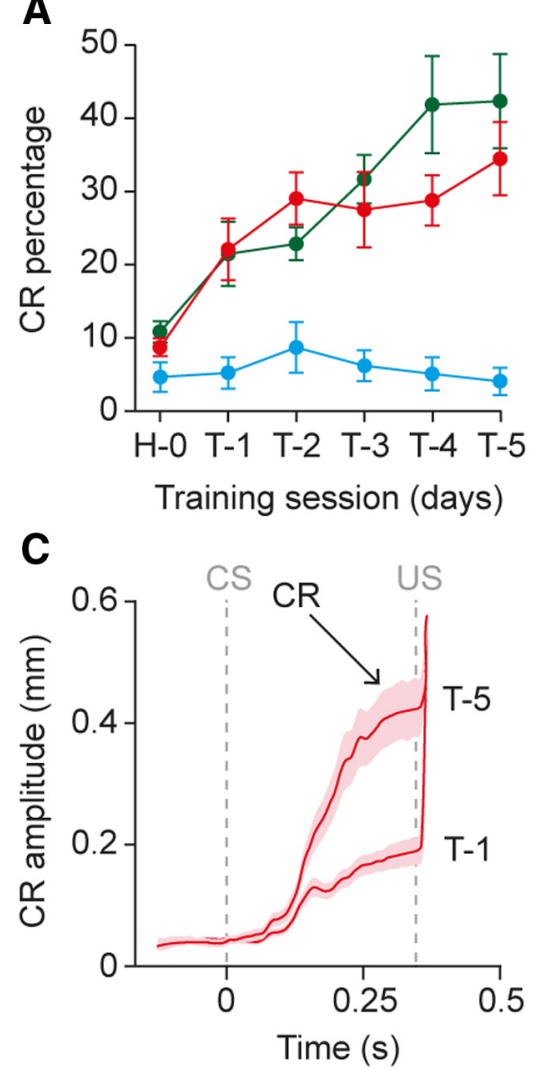

B

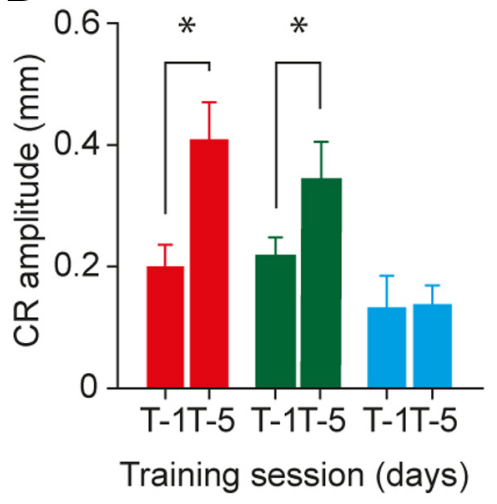

D

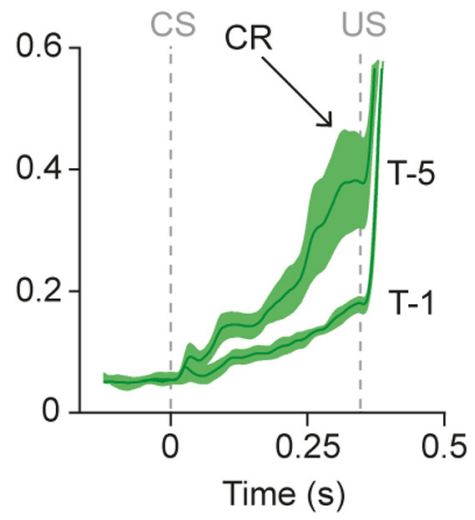

Figure 4. Eyeblink conditioning after paired and pseudopaired presentation of CS and US. $\boldsymbol{A}$, The mean percentage of CRs per daily training session (T-1-T-5) gradually increased for animals that were trained with a paired presentation of the CS and US (red, conditioned with BDA injection in lateral right BPN; green, conditioned with BDA injection in medial right BPN), whereas pseudoconditioning with explicitly unpaired presentations of the CS and US did not result in CRs (blue). Before training, all animals were habituated ( $\mathrm{H}-0)$ to the experimental setup. $\boldsymbol{B}$, Animals that were subjected to a paired presentation of the $\mathrm{CS}$ and US also showed a significant increase of the amplitude of their eyelid CRs. ${ }^{*} p=0.027$, conditioned with BDA in lateral right BPN; ${ }^{*} p=0.04$, conditioned with BDA in medial right BPN. C, Average \pm SEM raw MDMT eyeblink traces of T1 and T5 for conditioned animals with $B D A$ injected in the lateral part of the right BPN. Maximum eyelid closure during the $C R$ was reached just before the onset of the US at 350 ms after CS onset. For comparison, a full eyelid closure (the unconditioned response) has an amplitude of $\sim 1 \mathrm{~mm}$. D, Same as $C$ but now for conditioned animals with BDA injected in the medial part of the right BPN.

pseudoconditioned group, BDA injections in the right BPN labeled on average $81 \pm 17$ mossy fibers in the MCP. As a joined $\mathrm{CN}$ total, we counted on average $7.77 \pm 2.13$ varicosities per labeled MCP fiber, of which $6.06 \pm 1.50$ were found in left $\mathrm{CN}$ and $1.71 \pm 0.72$ in the right $\mathrm{CN}$. Like in untrained animals, most labeling was found in the LCN (bilateral LCN, $3.30 \pm 0.86$; left $\mathrm{LCN}, 2.62 \pm 0.60$; right $\mathrm{LCN}, 0.68 \pm 0.26)$ and dorsolateral parts of the PIN (bilateral PIN, $3.27 \pm 0.98$; left PIN, $2.29 \pm 0.85$; right PIN, $0.98 \pm 0.54)$. In the DLH, labeled varicosities were also sparse after pseudoconditioning (bilateral DLH, $0.07 \pm 0.04$; left DLH, $0.06 \pm 0.04$; right DLH, $0.01 \pm 0.01$ ).

In conditioned animals with BDA injected in the medial parts of the right $\mathrm{BPN}$, which are non-auditory regions of the $\mathrm{BPN}$, collateral mossy fiber projections to the $\mathrm{CN}$ were extremely sparse (Figs. 5C, 6C; Table 1,2). These BDA injections resulted in $54 \pm 19$ labeled mossy fibers counted in both MCPs, each showing on average $1.65 \pm 0.20$ labeled $\mathrm{CN}$ varicosities (left $\mathrm{CN}$, $1.28 \pm 0.21$; right $\mathrm{CN}, 0.37 \pm 0.09)$. These varicosities were mainly found in the LCN (bilateral LCN, $1.07 \pm 0.15$; left LCN, $0.94 \pm 0.16$; right LCN, $0.14 \pm 0.09$ ) and PIN (bilateral PIN, $0.32 \pm 0.21$; left PIN, $0.16 \pm 0.12$; right PIN, $0.16 \pm 0.10$ ). In this group, the BPN-DLH projection was virtually absent (bilateral $\mathrm{DLH}, 0.14 \pm 0.08$; left DLH, $0.10 \pm 0.05$; right $\mathrm{DLH}, 0.04 \pm$
0.04). Between untrained, pseudoconditioned, and conditioned animals with BDA injected in the medial non-auditory part of the right BPN, no significant differences could be established (Table 2).

In contrast, conditioned mice with BDA injected in the lateral, potentially auditory, parts of the right BPN showed a more widespread pattern of labeled mossy fibers and varicosities in the $\mathrm{CN}$ (Figs. $5 D$, $6 D, 7$; Tables 1, 2). Interestingly, this increase was not only found in the left $\mathrm{CN}$, which is ipsilateral to the US, but also in the right $\mathrm{CN}$ contralateral to the US. These injections resulted on average in $224 \pm 44$ mossy fibers in the MCP, with, for each fiber, on average $19.10 \pm 3.91$ labeled $\mathrm{CN}$ varicosities (left CN, $7.59 \pm$ 0.97 ; right $\mathrm{CN}, 11.51 \pm 3.06)$. These values are significantly higher compared with the three control groups (bilateral $\mathrm{CN}, p=0.001$; left $\mathrm{CN}, p=0.006$; right $\mathrm{CN}, p=0.004$; one-way ANOVA; Table $2)$. The increased amount of varicosities per MCP mossy fiber was most robust in the bilateral DLH regions (bilateral DLH, $1.67 \pm 0.34$; left DLH, $0.66 \pm 0.15$; right $\mathrm{DLH}, 1.01 \pm 0.23$; all comparisons $p<$ 0.001, all one-way ANOVA; Fig. 7D; Table 2).

\section{Correlation between number of varicosities and amplitude of CRs} The results presented above suggest that the process of pavlovian eyeblink conditioning corresponds to an increase in the number of varicosities/labeled MCP fiber. Therefore, we examined the potential correlation between the success of the conditioning procedure and the average number of labeled varicosities. Our data showed a significant correlation between the number of labeled varicosities in the DLH per MCP mossy fiber and the amplitude of eyelid CRs in the last training sessions. In other words, more mossy fiber collaterals to the DLH resulted in a larger eyelid CR. This correlation was found for the DLH on both sides of the cerebellum and could not, except for the total left AIN region including the adjacent DLH, be established for any other region of the CN (bilateral DLH, Pearson's correlation $=0.762, p=0.004$; left DLH, Pearson's correlation $=0.803, p=0.002$; right DLH, Pearson's correlation $=0.601, p=0.039$; Fig. 8$)$.

\section{Discussion}

Eyeblink conditioning can induce axonal outgrowth and synaptogenesis in the $\mathrm{CN}$

The current study shows that robust axonal outgrowth and synaptogenesis can be induced in the adult cerebellum while learning a new specific associative motor task. We show that input from potentially auditory mossy fiber collaterals to the $\mathrm{CN}$ expands considerably after pavlovian eyeblink conditioning to a tone, whereas no changes are observed after pseudoconditioning to this tone. In both untrained and pseudoconditioned animals, labeling is sparse and limited to the LCN and caudolateral PIN, a 
A B23: Untrained

BDA injection: lateral BPN
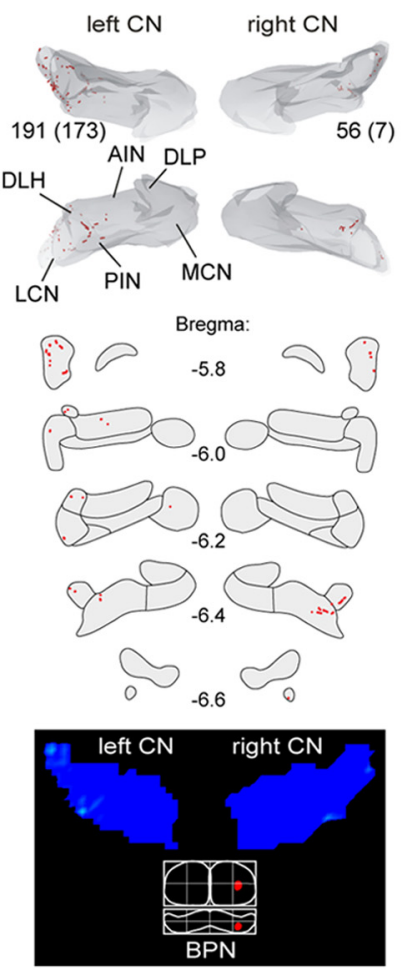

B B73: Pseudo-conditioned $\mathrm{BDA}$ injection: lateral BPN
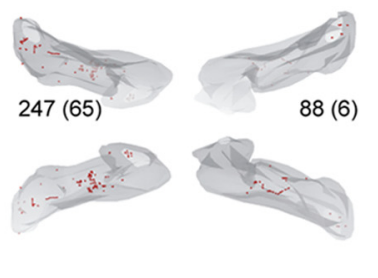

$88(6)$
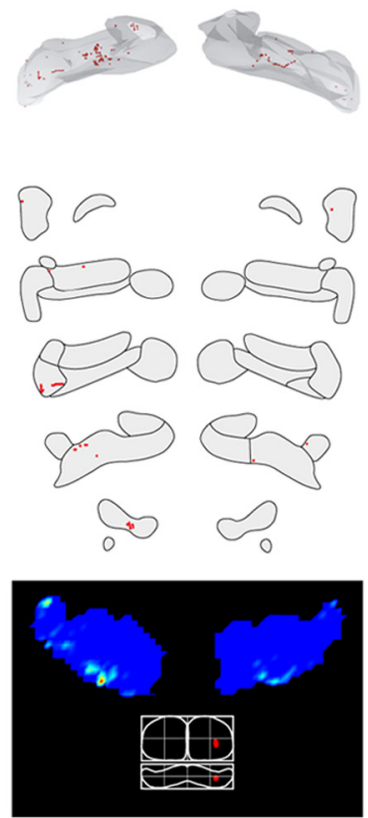

C

B89: Conditioned

BDA injection: medial BPN

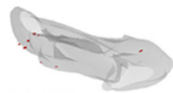

$36(85)$

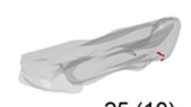

25 (10)
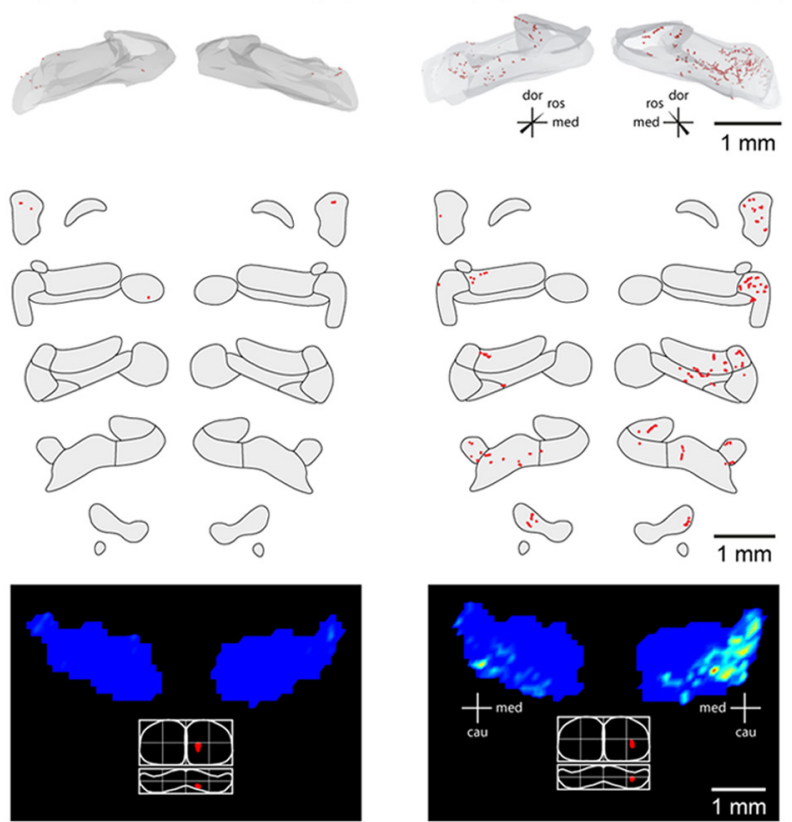

Figure 5. Differences in collateralization of pontine mossy fibers after conditioning. Four examples of each experimental group are shown. Top, Three-dimensional reconstruction based on every other section through the $\mathrm{CN}$. The bottom pair of reconstructions represent caudal view of the left and right hand nuclei; the top pair represents an inverted rostral view. Numbers between reconstruction pairs indicate number of plotted varicosities and number of labeled fibers within the MCP (between brackets). Middle, Labeled varicosities in the bilateral CN plotted in standardized sections going from bregma $-5.8 \mathrm{to}-6.6 \mathrm{~mm}$. Bottom, Dorsal view of the $C N$ showing the density profile determined from counting the number of plotted varicosities in mediolateral bins of $80 \mu \mathrm{m}$ wide per section and visualized with MATLAB routines. Bottom shows a dorsal and caudal view of the BPN with a representation of the injection site. Note that, in all groups, the number of labeled fibers is highest in the contralateral MCP. The number of plotted varicosities/labeled fibers is highest ipsilaterally of the conditioned eye. Scale bars, $1 \mathrm{~mm}$. DLP, Dorsolateral protuberance; MCN, medial cerebellar nucleus.

finding that has been reported previously for other species (Dietrichs et al., 1983, Brodal et al., 1986; Parenti et al., 2002; Cicirata et al., 2005). Because pseudoconditioned animals show similar patterns of labeling as untrained animals, the data strongly suggest that the changed distribution and increased density of terminal labeling in the conditioned animals are specifically attributable to the paired presentation of CS and US rather than to the less specific aspects of the learning task, such as habituation or sensitization to the CS and US. Because the number of varicosities in the $\mathrm{CN}$ per fiber in the MCP seems to be slightly higher in the pseudoconditioned group compared with the untrained group, one could argue that there might be a minor effect of the pseudoconditioning similar to observations done by Foscarin et al. (2011) who noted that environmental enrichment might contribute to plasticity in the CN. However, because the difference between the pseudoconditioned and untrained animals is far from significant (overall $p=0.832$ ), we refrain from making any speculations on this point. In addition, no changes are observed in conditioned animals after labeling nonauditory mossy fibers from the medial part of the BPN, which in fact, result in even lower amounts of varicosities/fiber compared with untrained and pseudoconditioned animals, which is also in line with previous work (Parenti et al., 2002; Cicirata et al., 2005). Therefore, we suggest that the observed conditioning-induced neuronal outgrowth specifically involves BPN neurons that transmit the tone $\mathrm{CS}$ to the $\mathrm{CN}$.

\section{CS and US pathway and bilateral contribution of the $\mathrm{CN}$ to eyeblink conditioning}

Pavlovian eyeblink conditioning is one of the best-characterized behavioral models of motor memory formation and associative learning for which the underlying neuroanatomical circuits have been described in detail. The air puff signal (US) is relayed by climbing fibers from the medial part of the dorsal accessory inferior olive and/or dorsomedial group of the principal olive to PCs in the C3 or D0 zones of the cerebellar cortex (Mostofi et al., 2010). These olivary parts also give rise to collaterals to the lateral part of the AIN and DLH, respectively (Ruigrok and Voogd, 2000; Pijpers et al., 2005; Sugihara and Shinoda, 2007). Moreover, these $\mathrm{CN}$ regions have been shown to influence those parts of the facial nucleus that control the eyelid muscles (Morcuende et al., 2002; Gonzalez-Joekes and Schreurs, 2012). The tone signal (CS) is thought to be relayed to the same PCs in the C3 and D0 zones of the cerebellar cortex by mossy fibers originating from the lateral part of the BPN (Leergaard and Bjaalie, 2007; Halverson and Freeman, 2010; Mostofi et al., 2010), However, neuronal projections from the lateral part of the BPN to the lateral AIN and DLH in naive mammals have been described as very sparse (Dietrichs et al., 1983; Brodal et al., 1986; Parenti et al., 2002; Cicirata et al., 2005). Our data support the hypothesis that this projection can be substantiated during conditioning. Interestingly, the increase in varicosities occurred bilaterally, which is in line with the notions that (1) eyeblink conditioning with a unilateral US re- 
A Untrained $(n=8)$

BDA injection: lateral BPN
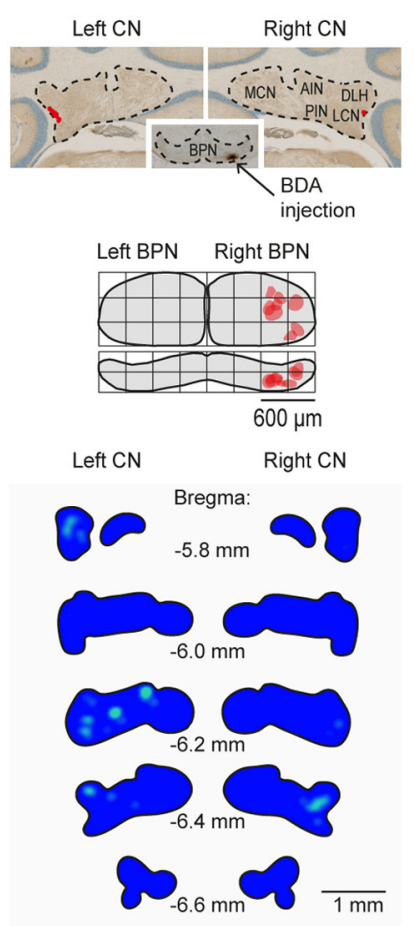

B Pseudo-conditioned $(n=5)$ BDA injection: lateral BPN

Left CN
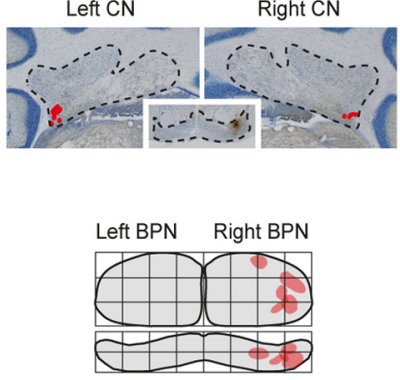

Left CN

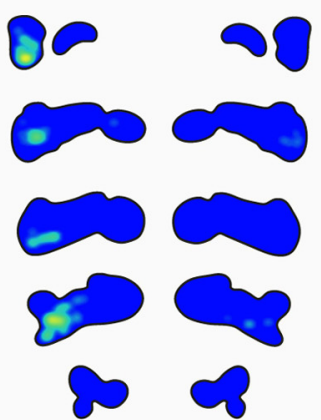

C Conditioned $(n=5)$

BDA injection: medial BPN

Left CN
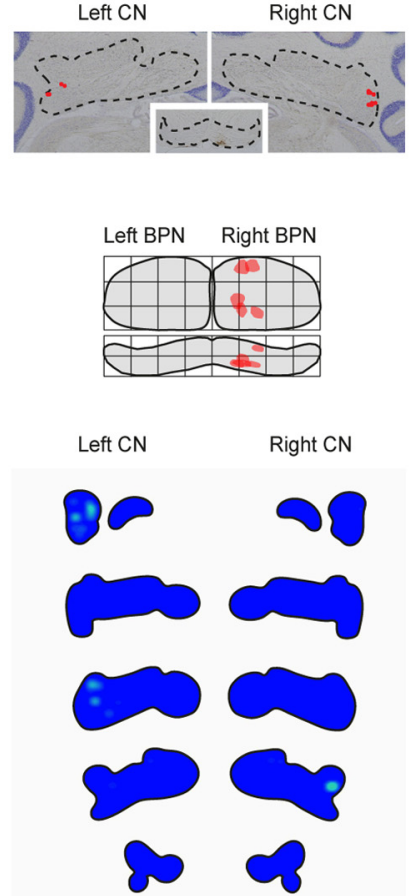

D Conditioned $(n=12)$

BDA injection: lateral BPN
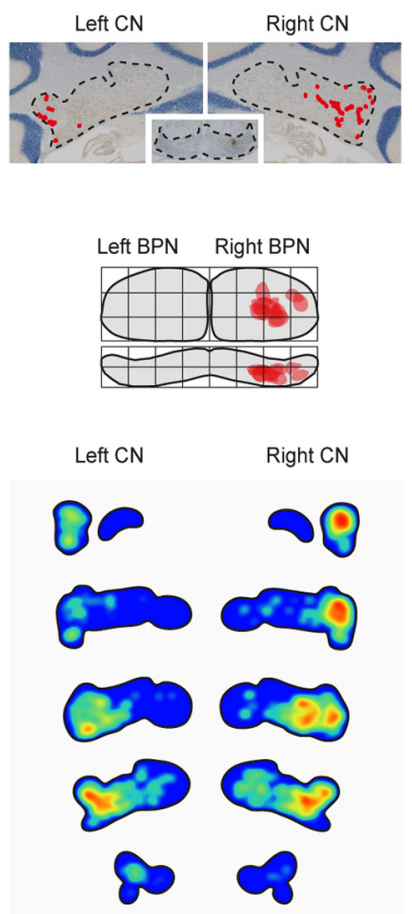

Figure 6. Expansion of mossy fiber collaterals in CN induced by eyeblink conditioning. Top, BDA tracer injections in the BPN and the labeling in the CN for an untrained, a pseudoconditioned, a conditioned animal with medial BDA injection in the BPN, and a conditioned animal with lateral BDA injection in the BPN. Each red dot represents a labeled varicosity. Middle, Dorsal (top panel) and caudal view (bottom panel) of the BPN with a representation of the BDA injection site. Bottom, Mean color-coded density plots for the number of varicosities per mossy fiber in the MCP for all animals per group from bregma -5.8 to -6.6 corrected for group size and the number of labeled varicosities in the MCP. MCN, Medial cerebellar nucleus.

sults in bilateral CRs (Campolattaro and Freeman, 2009), (2) the cerebellar side contralateral to the US also contributes to $\mathrm{CR}$ (Ivarsson and Hesslow, 1993), (3) trigemino-olivary projections are bilateral (De Zeeuw et al., 1996), and (4) inactivation of PCs ipsilateral to the eye puff before conditioning cannot completely prevent the occurrence of CRs during training (Gruart and Yeo, 1995).

The potential role of mossy fiber collaterals: strengthening cerebellar output

During pavlovian eyeblink conditioning, the outgrowth of the mossy fiber collaterals occurs particularly in the part of the $\mathrm{CN}$, which receives input from PCs known to be involved in controlling eyelid movements, namely the DLH (Morcuende et al., 2002; Mostofi et al., 2010; Gonzalez-Joekes and Schreurs, 2012). We propose that this new excitatory input to the $\mathrm{DLH}$, and adjacent lateral AIN, interacts with the well timed PC disinhibition of the same DLH neurons (Medina et al., 2000; Witter et al., 2013) and results in a stronger output to the eyelid muscles than would happen with changes in the PC input alone (Fig. 9). In addition, it has been shown that excitatory mossy fiber input followed by inhibitory PC input could induce LTP at the mossy fiber-CN neuron synapse (Pugh and Raman 2008). Therefore, one would expect a positive correlation between the amount of mossy fibers collaterals to the DLH region and the amplitude of the eyelid CRs. Indeed, the increase in the number of mossy fiber varicosities in this DLH region specifically is positively correlated to the amplitude of the eyelid CRs at the end of the learning process.
Adult neurons maintain the capacity for axonal growth and synapse formation

Although many adult neurons maintain the capacity for axonal growth and synapse formation (Holtmaat and Svoboda, 2009), evidence is limited for learning-induced reorganizations, such as axonal growth over longer distances and new synapse formation. Conversely, hormone-induced growth of descending fibers in the spinal cord can occur in relation to seasonal sexual activity (VanderHorst and Holstege, 1997; Gerrits et al., 2008), and axons in the adult brain can grow and branch over distances of millimeters during repair after brain damage (Dancause et al., 2005). Because this reorganization of neuronal circuits by axonal growth in principle could also contribute to the memory storage capacity of the brain, it has been recognized as a plausible mechanism for learning and memory formation for many decades (Holt, 1931; Wen et al., 2009). However, evidence for this mechanism has been hampered by technical challenges and by finding a learning model in which (1) the essential neuronal pathways are known in considerable detail and (2) for which synaptic and intrinsic plasticity within these pathways are inadequate to fully explain the process of memory formation and consolidation. In the present study, we have shown that pavlovian eyeblink conditioning fulfills both conditions and that anatomical changes in the underlying circuitry that occur during learning present a compelling case.

Learning-dependent synapse formation in other studies

To our knowledge, this study is one of the first to describe robust anatomical changes occurring in the adult mammalian brain during learning. Although morphological changes occurring 
Table 1. Mean \pm SEM number of BDA-labeled varicosities in CN and BDA-labeled fibers in the MCP

\begin{tabular}{|c|c|c|c|c|}
\hline & $\begin{array}{l}\text { Untrained BDA in lateral BPN } \\
\text { (animals } n=8 \text { ) }\end{array}$ & $\begin{array}{l}\text { Pseudoconditioned BDA in lateral BPN } \\
\text { (animals } n=5 \text { ) }\end{array}$ & $\begin{array}{l}\text { Conditioned BDA in medial BPN } \\
\text { (animals } n=5 \text { ) }\end{array}$ & $\begin{array}{l}\text { Conditioned BD } \\
\text { (animals } n=1\end{array}$ \\
\hline \multicolumn{5}{|c|}{ Mean \pm SEM number of BDA-labeled varicosities in CN } \\
\hline \multicolumn{5}{|c|}{ Bilateral } \\
\hline $\mathrm{CN}$ & $481 \pm 138$ & $621 \pm 158$ & $92 \pm 36$ & $4463 \pm 1314$ \\
\hline Lateral CN & $285 \pm 86$ & $273 \pm 78$ & $52 \pm 14$ & $1980 \pm 547$ \\
\hline Interposed CN & $189 \pm 59$ & $307 \pm 93$ & $37 \pm 26$ & $2000 \pm 606$ \\
\hline PIN & $105 \pm 45$ & $286 \pm 93$ & $17 \pm 12$ & $1040 \pm 303$ \\
\hline AIN & $85 \pm 36$ & $21 \pm 10$ & $19 \pm 14$ & $960 \pm 322$ \\
\hline DLH & $30 \pm 18$ & $6 \pm 3$ & $11 \pm 8$ & $391 \pm 149$ \\
\hline Medial CN & $7 \pm 2$ & $41 \pm 30$ & $0 \pm 0$ & $483 \pm 199$ \\
\hline \multicolumn{5}{|l|}{ Left CN } \\
\hline $\mathrm{CN}$ & $343 \pm 98$ & $502 \pm 140$ & $71 \pm 31$ & $1676 \pm 362$ \\
\hline Lateral CN & $185 \pm 52$ & $218 \pm 61$ & $42 \pm 11$ & $678 \pm 158$ \\
\hline Interposed CN & $151 \pm 52$ & $245 \pm 92$ & $26 \pm 20$ & $722 \pm 147$ \\
\hline PIN & $82 \pm 36$ & $266 \pm 94$ & $14 \pm 13$ & $425 \pm 107$ \\
\hline AIN & $70 \pm 37$ & $19 \pm 11$ & $12 \pm 8$ & $297 \pm 73$ \\
\hline DLH & $22 \pm 17$ & $6 \pm 3$ & $6 \pm 4$ & $136 \pm 43$ \\
\hline Medial CN & $7 \pm 2$ & $40 \pm 31$ & $0 \pm 0$ & $266 \pm 111$ \\
\hline \multicolumn{5}{|l|}{ Right CN } \\
\hline $\mathrm{CN}$ & $138 \pm 52$ & $118 \pm 33$ & $21 \pm 9$ & $2787 \pm 976$ \\
\hline Lateral CN & $100 \pm 46$ & $55 \pm 18$ & $10 \pm 8$ & $1292 \pm 422$ \\
\hline Interposed CN & $38 \pm 14$ & $62 \pm 31$ & $11 \pm 6$ & $1277 \pm 473$ \\
\hline PIN & $23 \pm 11$ & $60 \pm 29$ & $3 \pm 2$ & $615 \pm 220$ \\
\hline AIN & $15 \pm 10$ & $2 \pm 1$ & $8 \pm 6$ & $663 \pm 266$ \\
\hline DLH & $8 \pm 7$ & $1 \pm 1$ & $5 \pm 4$ & $256 \pm 112$ \\
\hline Medial CN & $0 \pm 0$ & $1 \pm 1$ & $0 \pm 0$ & $218 \pm 91$ \\
\hline \multicolumn{5}{|c|}{ Mean \pm SEM number of BDA-labeled fibers in MCP } \\
\hline Bilateral MCP & $120 \pm 30$ & $81 \pm 17$ & $54 \pm 19$ & $224 \pm 44$ \\
\hline Left MCP & $108 \pm 27$ & $69 \pm 15$ & $49 \pm 17$ & $155 \pm 29$ \\
\hline Right MCP & $12 \pm 4$ & $12 \pm 4$ & $5 \pm 2$ & $59 \pm 18$ \\
\hline
\end{tabular}

Mean \pm SEM number of labeled varicosities in the specified regions of the cerebellar nuclei (CN) (top) and number of labeled mossy fibers in the MCP (bottom) per experimental group. In all groups, BDA was injected in the right BPN. Note that, in untrained animals $(n=8)$, pseudoconditioned animals $(n=5)$, and conditioned animals with BDA injected in the medial BPN $(n=5)$, most labeled varicosities were found in the LCN and PIN. In these groups, labeled varicosities in the DLH region are extremely sparse. In conditioned animals with BDA injected in the lateral BPN, there is a widespread increase in varicosities.

Table 2. Mean \pm SEM number of labeled varicosities in CN per labeled mossy fiber in the MCP

\begin{tabular}{|c|c|c|c|c|c|c|c|c|c|}
\hline & \multirow{2}{*}{$\begin{array}{l}\text { Untrained BDA in } \\
\text { lateral BPN animals } \\
(n=8)\end{array}$} & \multirow{2}{*}{$\begin{array}{l}\text { Pseudoconditioned BDA in } \\
\text { lateral BPN animals } \\
(n=5)\end{array}$} & \multirow{2}{*}{$\begin{array}{l}\text { Conditioned BDA in } \\
\text { medial BPN animals } \\
(n=5)\end{array}$} & \multirow{2}{*}{$\begin{array}{l}\text { Conditioned BDA in } \\
\text { lateral BPN animals } \\
(n=12)\end{array}$} & \multirow{2}{*}{$\begin{array}{l}\text { Varicosities/MCP } \\
\text { fiber (ANOVA, } \\
p \text { value) }\end{array}$} & \multicolumn{4}{|c|}{ Tukey-Kramer post hoc $p$ value } \\
\hline & & & & & & $\mathrm{Cl}-\mathrm{Un}$ & CI-Ps & $\mathrm{Cl}-\mathrm{Cm}$ & $\begin{array}{l}\text { Cm-Un Ps-Un } \\
\text { Ps-Cm }\end{array}$ \\
\hline CN & $4.46 \pm 1.32$ & $7.77 \pm 2.13$ & $1.65 \pm 0.20$ & $19.10 \pm 3.91$ & 0.001 & 0.012 & 0.015 & 0.010 & n.s. \\
\hline Lateral CN & $2.21 \pm 0.49$ & $3.30 \pm 0.86$ & $1.07 \pm 0.15$ & $8.44 \pm 1.50$ & 0.001 & 0.008 & 0.084 & 0.007 & n.s. \\
\hline Interposed CN & $2.11 \pm 0.93$ & $3.64 \pm 1.10$ & $0.55 \pm 0.21$ & $8.57 \pm 1.54$ & 0.001 & 0.012 & 0.150 & 0.007 & n.s. \\
\hline PIN & $1.24 \pm 0.50$ & $3.27 \pm 0.98$ & $0.32 \pm 0.21$ & $4.52 \pm 0.94$ & 0.007 & 0.050 & 0.814 & 0.027 & n.s. \\
\hline Medial CN & $0.14 \pm 0.08$ & $0.83 \pm 0.67$ & $0.00 \pm 0.00$ & $2.10 \pm 0.84$ & 0.124 & 0.232 & 0.713 & 0.302 & n.s. \\
\hline \multicolumn{10}{|l|}{ Left CN } \\
\hline $\mathrm{CN}$ & $3.67 \pm 1.39$ & $6.06 \pm 1.50$ & $1.28 \pm 0.21$ & $7.59 \pm 0.97$ & 0.006 & 0.065 & 0.818 & 0.006 & n.s. \\
\hline Lateral CN & $1.64 \pm 0.48$ & $2.62 \pm 0.60$ & $0.94 \pm 0.16$ & $3.12 \pm 0.49$ & 0.029 & 0.131 & 0.911 & 0.037 & n.s. \\
\hline Interposed CN & $1.89 \pm 0.95$ & $2.63 \pm 0.81$ & $0.31 \pm 0.18$ & $3.32 \pm 0.38$ & 0.029 & 0.323 & 0.887 & 0.020 & n.s. \\
\hline PIN & $1.11 \pm 0.50$ & $2.29 \pm 0.85$ & $0.16 \pm 0.12$ & $1.95 \pm 0.48$ & 0.098 & 0.691 & 0.972 & 0.141 & n.s. \\
\hline $\mathrm{CN}$ & $0.79 \pm 0.25$ & $1.71 \pm 0.72$ & $0.37 \pm 0.09$ & $11.51 \pm 3.06$ & 0.004 & 0.011 & 0.060 & 0.027 & n.s. \\
\hline Lateral CN & $0.57 \pm 0.22$ & $0.68 \pm 0.26$ & $0.14 \pm 0.09$ & $5.32 \pm 1.40$ & 0.004 & 0.015 & 0.051 & 0.025 & n.s. \\
\hline Interposed CN & $0.22 \pm 0.08$ & $1.01 \pm 0.55$ & $0.23 \pm 0.10$ & $5.25 \pm 1.35$ & 0.004 & 0.007 & 0.069 & 0.024 & n.s. \\
\hline PIN & $0.13 \pm 0.07$ & $0.98 \pm 0.54$ & $0.16 \pm 0.10$ & $2.57 \pm 0.75$ & 0.018 & 0.026 & 0.342 & 0.070 & n.s. \\
\hline AIN & $0.09 \pm 0.05$ & $0.03 \pm 0.02$ & $0.08 \pm 0.06$ & $2.68 \pm 0.66$ & 0.001 & 0.004 & 0.013 & 0.014 & n.s. \\
\hline DLH & $0.05 \pm 0.04$ & $0.01 \pm 0.01$ & $0.04 \pm 0.04$ & $1.01 \pm 0.23$ & 0.000 & 0.002 & 0.006 & 0.008 & n.s. \\
\hline Medial CN & $0.00 \pm 0.00$ & $0.01 \pm 0.01$ & $0.00 \pm 0.00$ & $0.94 \pm 0.37$ & 0.056 & 0.100 & 0.204 & 0.191 & n.s. \\
\hline
\end{tabular}

Mean \pm SEM number of labeled varicosities per fiber mossy fiber in the MCP specified for different regions of the cerebellar nuclei (CN). No significant differences were found between the untrained group, the pseudoconditioned group, and the conditioned group with BDA injected in non-auditory medial parts of the right BPN. Conditioned animals with BDA injected in lateral auditory parts of the right BPN instead show a significant bilateral increase of varicosities per labeled mossy fiber in the MCP. Compared with the three control groups, this increase was most robust in the DLH region. Cl, Conditioned with BDA injection in lateral right BPN, Cm, conditioned with BDA injection in medial right BPN; Ps, pseudoconditioned with BDA injected in lateral right BPN; Un, untrained with BDA injected in lateral right BPN. 


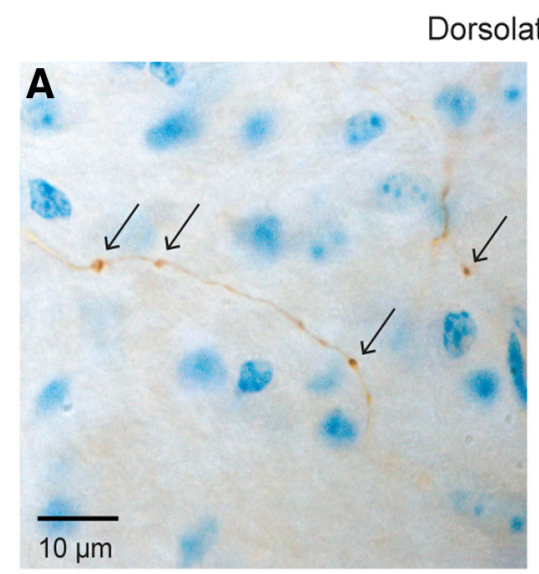

\section{Middle cerebellar peduncle}

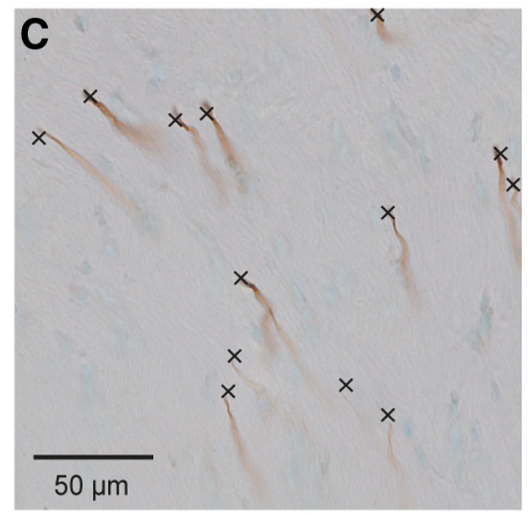

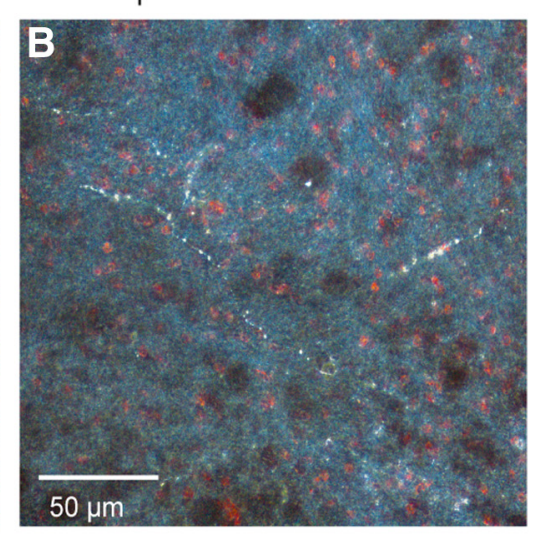

Dorsolataral hump

D

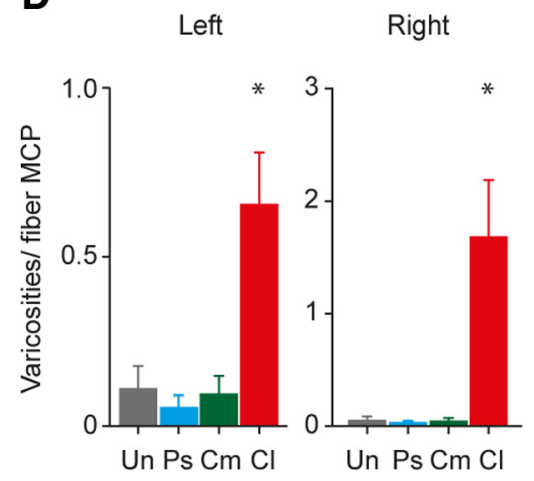

Figure 7. Labeled mossy fiber collaterals and varicosities in the DLH of conditioned animals with BDA injected in the lateral part of the right BPN. $\boldsymbol{A}$, Light microscopic image of a BDA-labeled mossy fiber collateral with varicosities in the DLH region of a conditioned animal. Scale bar, $10 \mu \mathrm{m}$. Arrows indicate labeled varicosities. B, Dark-field microscopic image of BDA-labeled mossy fiber collaterals with varicosities in the DLH region of a conditioned animal. Scale bar, $50 \mu \mathrm{m}$. C, BDA-labeled mossy fibers in the $M C P$, which were used to correct for the size of the BDA injection, by dividing the number of labeled varicosities in the CN by the number of labeled fibers in the MCP. Scale bar, $50 \mu \mathrm{m}$. D, Total number of synapses in the DLH per labeled MCP fiber for all four groups. Conditioned animals with BDA injection in the lateral right BPN show a significant increase in their number of varicosities per fiber in the MCP. Cl, Conditioned with BDA injection in the lateral right BPN; $\mathrm{Cm}$, conditioned with BDA injection in the medial right BPN; Ps, pseudoconditioned with BDA injected in the lateral right BPN; Un, untrained with BDA injected in the lateral right BPN. * $p$ value left DLH 0.003; $p$ value right DLH $<0.001$.

during eyeblink conditioning have been described, they were restricted to ultrastructural synaptic features in the $\mathrm{CN}$ (i.e., vesicle density after delay conditioning; Weeks et al., 2007) and hippocampus (formation of multiple synapse boutons after trace conditioning; Geinisman et al., 2001). The best suggestion of learning-induced formation of new boutons in the $\mathrm{CN}$ was provided by Kleim et al. (2002) who reported a conditioninginduced net increase of the number of synapses per neuron in the AIN. However, this conclusion seems to be based on a decreased number of neurons. Moreover, this study could not show that the increased number of synapses were mossy fiber collaterals originating from auditory parts of the BPN.

\section{Learning in two stages: memory transfer}

Recent models on pavlovian eyeblink conditioning suggest that the initial memory is formed in the cerebellar cortex and that long-term memory storage also occurs in the $\mathrm{CN}$ downstream (Medina et al., 2000; Ohyama et al., 2006). In this concept, the rate of expression of conditioned eyelid responses is supposed to be determined by activity in the $\mathrm{CN}$ and CRs that remain present after inactivating the cerebellar cortex are assumed to be attributable to plasticity in the CN. However, these models have been

debated, because, as mentioned above, the main neuronal pathway that was hypothesized to mediate the long-term memory storage, i.e., the projection from the BPN to the lateral AIN and DLH, appeared virtually absent after standard tracing experiments in naive animals. Here we have shown that this "missing projection" can be newly formed during pavlovian eyeblink conditioning.

Similar mechanisms of functional memory transfer have been suggested for adaptation of the vestibulo-ocular reflex (du Lac et al., 1995; Raymond et al., 1996; Wulff et al., 2009; Okamoto et al. 2011), for which the vestibular nuclei form the main downstream target area. Possibly, the interaction that may take place between cerebellar input and its output region during procedural memory formation may have its counterpart in other brain systems, such as that formed by the hippocampus and downstream neurons in the cerebral cortex, which control declarative memory formation and consolidation (Lesburguères et al., 2011). Neurons in the orbitofrontal cortex probably undergo an "early tagging process" during encoding to ensure putative hippocampal-driven rewiring of downstream cortical networks that support remote memory storage. This process is also information specific and capable of modulating remote memory persistence with improved retrieval similar to what we propose here for the CN. Thus, if hippocampal-cerebral cortical learning indeed also involves synthesis of fibers, the process of axonal targeting and rewiring that we show here for cerebellar learning might represent a common mechanism for memory consolidation in the brain.

\section{References}

Boele HJ, Koekkoek SK, De Zeeuw CI (2010) Cerebellar and extracerebellar involvement in mouse eyeblink conditioning: the ACDC model. Front Cell Neurosci 3:19. CrossRef Medline

Brodal P, Dietrichs E, Walberg F (1986) Do pontocerebellar mossy fibres give off collaterals to the cerebellar nuclei? An experimental study in the cat with implantation of crystalline HRP-WGA. Neurosci Res 4:12-24. CrossRef Medline

Campolattaro MM, Freeman HJ (2009) Examination of bilateral eyeblink conditioning in rats. Behav Neurosci 6:1346-1352.

Cicirata F, Zappalà A, Serapide MF, Parenti R, Pantò MR, Paz C (2005) Different pontine projections to the two sides of the cerebellum. Brain Res Brain Res Rev 49:280-294. CrossRef Medline

Dancause N, Barbay S, Frost SB, Plautz EJ, Chen D, Zoubina EV, Stowe AM, Nudo RJ (2005) Extensive cortical rewiring after brain injury. J Neurosci 25:10167-10179. CrossRef Medline

De Zeeuw CI, Yeo CH (2005) Time and tide in cerebellar memory formation. Curr Opin Neurobiol 15:667-674. CrossRef Medline

De Zeeuw CI, Lang EJ, Sugihara I, Ruigrok TJ, Eisenman LM, Mugnaini E, Llinás R (1996) Morphological correlates of bilateral synchrony in the rat cerebellar cortex. J Neurosci 10:3412-3426. Medline

Dietrichs E, Bjaalie JG, Brodal P (1983) Do pontocerebellar fibers send collaterals to the cerebellar nuclei? Brain Res 17:127-131. Medline 
Lateral CN

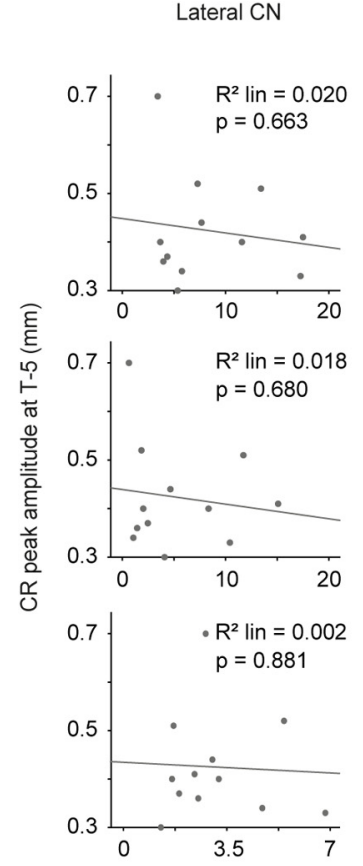

Posterior IN
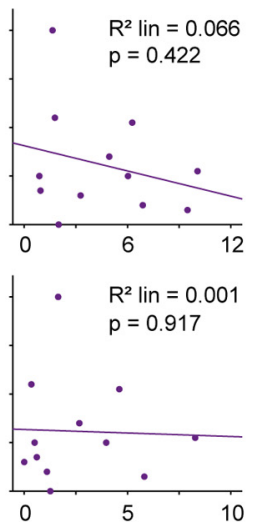

. $\quad R^{2}$ lin $=0.202$

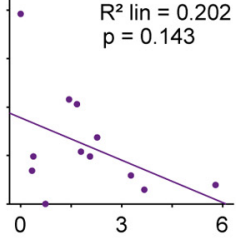

Anterior IN

Dorsolateral hump

Medial CN
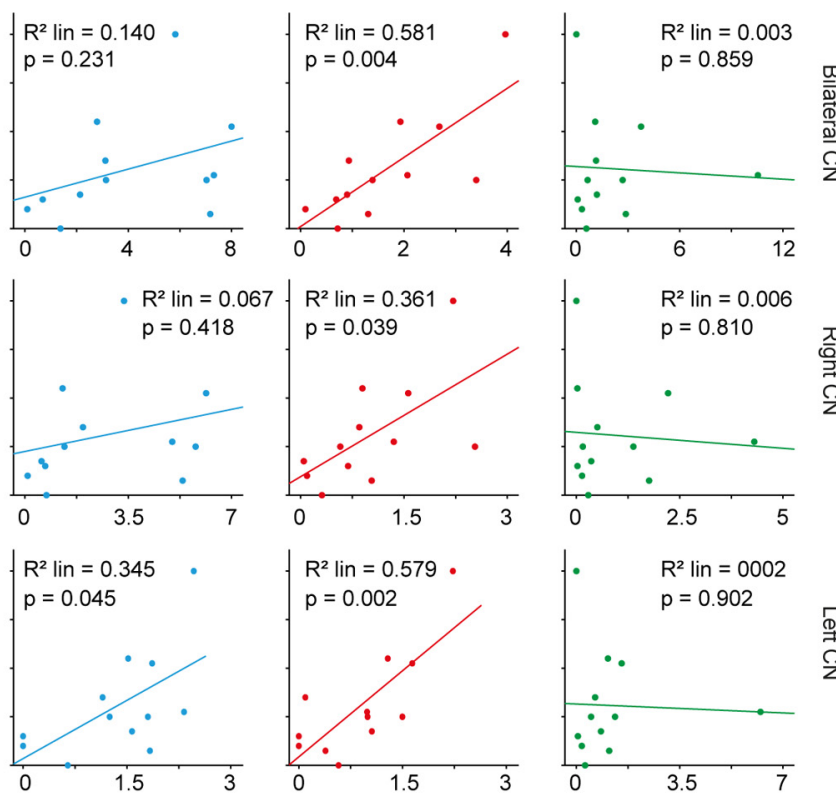

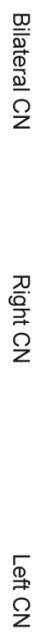

Figure 8. Mean number of labeled varicosities per labeled mossy fiber in the MCP plotted against the mean CR amplitude (millimeters) at the last training session for conditioned animals with BDA injected in the lateral BPN. Top panels are for the bilateral CN, middle panels for the right $\mathrm{CN}$, and bottom panels for the left CN. In conditioned animals, the number of labeled varicosities in the DLH per MCP fiber correlates positively with the amplitude of the eyelid CRs in the last training sessions. This correlation was found for bilateral, left, and right DLH region. IN, Interposed nucleus.

Untrained
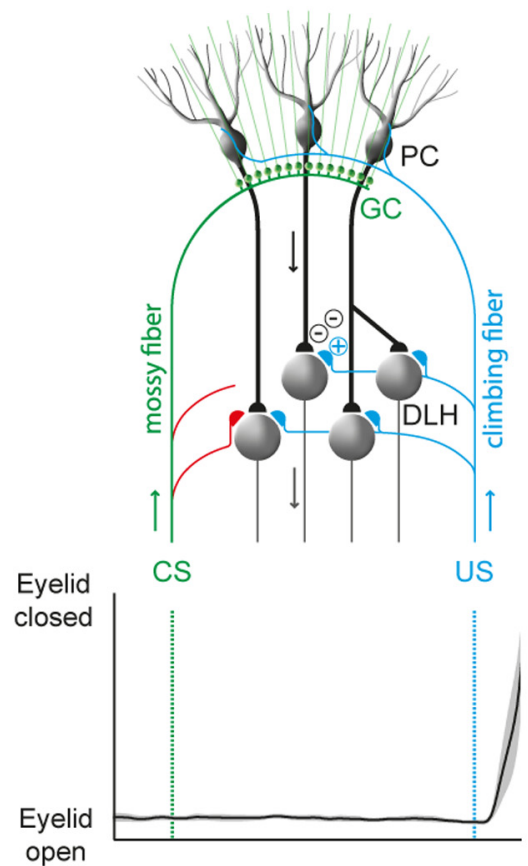

Time
Conditioned phase 1
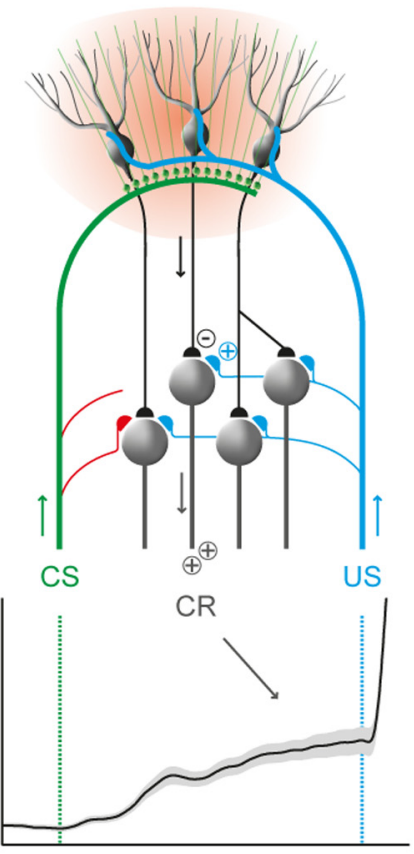

Time
Conditioned phase 2
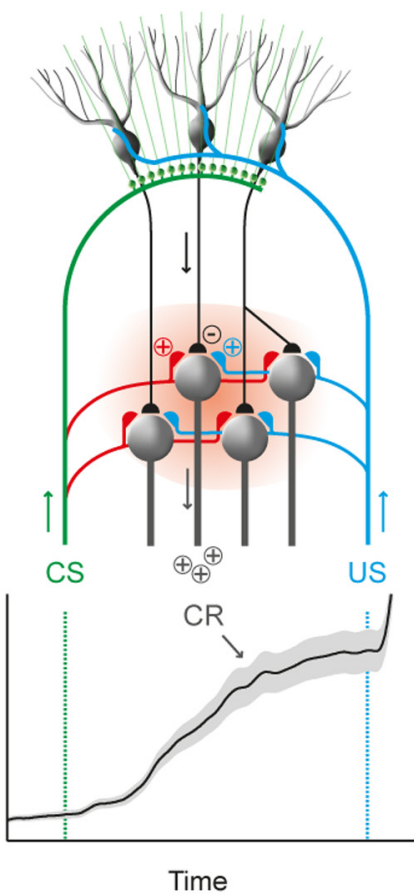

Figure 9. Proposed model showing how the cerebellar cortex and CN may both contribute to the learning process during pavlovian eyeblink conditioning. DLH neurons receive inhibitory PC input (black), excitatory climbing fiber input as the US (blue), and excitatory mossy fiber input as the CS (red) and innervate the eyelid muscles via the red nucleus and facial nucleus. In naive animals, the CS will not elicit a blink response. During the first phase of acquisition during eyeblink conditioning, plasticity is induced in the cerebellar cortex, resulting in a well timed PC firing pause (indicated by 2 minus symbols), which behaviorally is reflected with a small-amplitude CR. Prolonged training will induce growth of mossy fiber collateral to eyeblink-controlling neurons in the CN, which behaviorally is reflected with a larger-amplitude CR. GC, Granule cell. 
du Lac S, Raymond JL, Sejnowski TJ, Lisberger SG (1995) Learning and memory in the vestibulo-ocular reflex. Annu Rev Neurosci 18:409-441. CrossRef Medline

Foscarin S, Ponchione D, Pajaj E, Leto K, Gawlak M, Wilczynski GM, Rossi F, Carulli D (2011) Experience-dependent plasticity and modulation of growth regulatory molecules at central synapses. PLoS One 6:e16666. CrossRef Medline

Gao Z, van Beugen BJ, De Zeeuw CI (2012) Distributed synergistic plasticity and cerebellar learning. Nat Rev Neurosci 13:619-635. CrossRef Medline

Geinisman Y, Berry RW, Disterhoft JF, Power JM, Van der Zee EA (2001) Associative learning elicits the formation of multiple-synapse boutons. J Neurosci 21:5568-5573. Medline

Gerrits PO, Veening JG, Blomsma SA, Mouton LJ (2008) The nucleus pararetroambiguus: a new group of estrogen receptive cells in the caudal ventrolateral medulla of the female golden hamster. Horm Behav 53:329-341. CrossRef Medline

Gonzalez-Joekes J, Schreurs BG (2012) Anatomical characterization of a rabbit cerebellar eyeblink premotor pathway using pseudorabies and identification of a local modulatory network in anterior interpositus. J Neurosci 32:12472-12487. CrossRef Medline

Gruart A, Yeo CH (1995) Cerebellar cortex and eyeblink conditioning: bilateral regulation of conditioned responses. Exp Brain Res 104:431-448. Medline

Halverson HE, Freeman JH (2010) Medial auditory thalamic input to the lateral pontine nuclei is necessary for auditory eyeblink conditioning. Neurobiol Learn Mem 93:92-98. CrossRef Medline

Hesslow G (1994) Inhibition of classically conditioned eyeblink responses by stimulation of the cerebellar cortex in the decerebrate cat. J Physiol 476:245-256. Medline

Holt EB (1931) Animal drive and the learning process. New York: Macmillan.

Holtmaat A, Svoboda K (2009) Experience-dependent structural synaptic plasticity in the mammalian brain. Nat Rev Neurosci 10:647-658. CrossRef Medline

Ivarsson M, Hesslow G (1993) Bilateral control of the orbicularis oculi muscle by one cerebellar hemisphere in the ferret. Neuroreport 1993 4:11271130. Medline

Jirenhed DA, Bengtsson F, Hesslow G (2007) Acquisition, extinction, and reacquisition of a cerebellar cortical memory trace. J Neurosci 27:24932502. Medline

Kandler K, Herbert H (1991) Auditory projections from the cochlear nucleus to pontine and mesencephalic reticular nuclei in the rat. Brain Res 25:230-242. CrossRef Medline

Kleim JA, Freeman JH Jr, Bruneau R, Nolan BC, Cooper NR, Zook A, Walters D (2002) Synapse formation is associated with memory storage in the cerebellum. Proc Natl Acad Sci U S A 99:13228-13231. CrossRef Medline

Koekkoek SK, Den Ouden WL, Perry G, Highstein SM, De Zeeuw CI (2002) Monitoring kinetic and frequency-domain properties of eyelid responses in mice with magnetic distance measurement technique. J Neurophysiol 88:2124-2133. Medline

Leergaard TB, Bjaalie JG (2007) Topography of the complete corticopontine projection: from experiments to principal maps. Front Neurosci 1:211-223. CrossRef Medline

Lesburguères E, Gobbo OL, Alaux-Cantin $\mathrm{S}$, Hambucken $\mathrm{A}$, Trifilieff $\mathrm{P}$, Bontempi B (2011) Early tagging of cortical networks is required for the formation of enduring associative memory. Science 331:924-928. CrossRef Medline

Martin SJ, Grimwood PD, Morris RGM (2000) Synaptic plasticity and memory: an evaluation of the hypothesis. Annu Rev Neurosci 23:649711. CrossRef Medline

McCormick DA, Thompson RF (1984) Cerebellum: essential involvement in the classically conditioned eyelid response. Science 223:296-299. CrossRef Medline

Medina JF, Nores WL, Ohyama T, Mauk MD (2000) Mechanisms of cerebellar learning suggested by eyelid conditioning. Curr Opin Neurobiol 10:717-724. CrossRef Medline

Medina JF, Repa JC, Mauk MD, LeDoux JE (2002) Parallels between cerebellum- and amygdala-dependent conditioning. Nat Rev Neurosci 3:122-131. CrossRef Medline
Morcuende S, Delgado-Garcia JM, Ugolini G (2002) Neuronal premotor networks involved in eyelid responses: retrograde transneuronal tracing with rabies virus from the orbicularis oculi muscle in the rat. J Neurosci 22:8808-8818. Medline

Mostofi A, Holtzman T, Grout AS, Yeo CH, Edgley SA (2010) Electrophysiological localization of eyeblink-related microzones in rabbit cerebellar cortex. J Neurosci 30:8920-8934. CrossRef Medline

Ohyama T, Nores WL, Medina JF, Riusech FA, Mauk MD (2006) Learninginduced plasticity in deep cerebellar nucleus. J Neurosci 26:12656-12663. CrossRef Medline

Okamoto T, Endo S, Shirao T, Nagao S (2011) Role of cerebellar cortical protein synthesis in transfer of memory trace of cerebellum-dependent motor learning. J Neurosci 31:8958-8966. CrossRef Medline

Parenti R, Zappalà A, Serapide MF, Pantò MR, Cicirata F (2002) Projections of the basilar pontine nuclei and nucleus reticularis tegmenti pontis to the cerebellar nuclei of the rat. J Comp Neurol 452:115-127. CrossRef Medline

Pijpers A, Voogd J, Ruigrok TJ (2005) Topography of olivo-cortico-nuclear modules in the intermediate cerebellum of the rat. J Comp Neurol 492: 193-213. CrossRef Medline

Pugh JR, Raman IM (2008) Mechanisms of potentiation of mossy fiber EPSCs in the cerebellar nuclei by coincident synaptic excitation and inhibition. J Neurosci 28:10549-10560. CrossRef Medline

Raymond JL, Lisberger SG, Mauk MD (1996) The cerebellum: a neuronal learning machine? Science 272:1126-1131. Medline

Ruigrok TJ, Voogd J (2000) Organization of projections from the inferior olive to the cerebellar nuclei in the rat. J Comp Neurol 426:209-228. CrossRef Medline

Schonewille M, Belmeguenai A, Koekkoek SK, Houtman SH, Boele HJ, van Beugen BJ, Gao Z, Badura A, Ohtsuki G, Amerika WE, Hosy E, Hoebeek FE, Elgersma Y, Hansel C, De Zeeuw CI (2010) Purkinje cell-specific knockout of the protein phosphatase PP2B impairs potentiation and cerebellar motor learning. Neuron 67:618-628. CrossRef Medline

Sugihara I, Shinoda Y (2007) Molecular, topographic, and functional organization of the cerebellar nuclei: analysis by three-dimensional mapping of the olivonuclear projection and aldolase C labeling. J Neurosci 27: 9696-9710. CrossRef Medline

VanderHorst VG, Holstege G (1997) Estrogen induces axonal outgrowth in the nucleus retroambiguus-lumbosacral motoneuronal pathway in the adult female cat. J Neurosci 17:1122-1136. Medline

Weeks AC, Connor S, Hinchcliff R, LeBoutillier JC, Thompson RF, Petit TL (2007) Eye-blink conditioning is associated with changes is synaptice ultrastructure in the rabbit interposed nucleus. Learn Mem 14:385-389. CrossRef Medline

Wen Q, Stepanyants A, Elston GN, Grosberg AY, Chklovskii DB (2009) Maximization of the connectivity repertoire as a statistical principle governing the shapes of dendritic arbors. Proc Natl Acad Sci U S A 106 : 12536-12541. CrossRef Medline

Witter L, Canto CB, Hoogland TM, de Gruijl JR, De Zeeuw CI (2013) Strength and timing of motor responses mediated by rebound firing in the cerebellar nuclei after Purkinje cell activation. Front Neural Circuits 7:133. CrossRef Medline

Wouterlood FG, Groenewegen HJ (1985) Neuroanatomical tracing by use of Phaseolus vulgaris-leucoagglutinin (PHA-L): electron microscopy of PHA-L-filled neuronal somata, dendrites, axons and axon terminals. Brain Res 326:188-191. CrossRef Medline

Wouterlood FG, Jorritsma-Byham B (1993) The anterograde neuroanatomical tracer biotinylated dextran-amine: comparison with the tracer Phaseolus vulgaris-leucoagglutinin in preparations for electron microscopy. J Neurosci Methods 48:75-87. CrossRef Medline

Wulff $\mathrm{P}$, Schonewille M, Renzi M, Viltono L, Sassoè-Pognetto M, Badura A, Gao Z, Hoebeek FE, van Dorp S, Wisden W, Farrant M, De Zeeuw CI (2009) Synaptic inhibition of Purkinje cells mediates consolidation of vestibulo-cerebellar motor learning. Nat Neurosci 12:1042-1049. CrossRef Medline

Zhang W, Linden DJ (2003) The other side of the engram: experiencedriven changes in neuronal intrinsic excitability. Nat Rev Neurosci 4:885900. CrossRef Medline 